JEL Classification: G28, P34, G21

Keywords: stress testing, bank, Russia

\title{
Bank Stress Tests as an Information Device for Emerging Markets: The Case of Russia"
}

\author{
Zuzana FUNGÁČOVÁ—Bank of Finland, Institute for Economies in Transition (BOFIT) \\ and Institute of Economic Studies of Charles University in Prague \\ (zuzana.fungacova@bof.fi)
}

Petr JAKUBÍK—Czech National Bank and Institute of Economic Studies of Charles University in Prague (Jakubik@fsv.cuni.cz)

Abstract

The recent financial crisis emphasized the need for effective financial stability analyses and tools for detecting systemic risk. This paper looks at the assessment of banking sector resilience through stress testing. We argue such analyses are valuable even in emerging economies, which suffer from limited data availability, short time series, and structural breaks. We propose a top-down stress test methodology that employs relatively limited information to overcome this data problem. Moreover, as credit growth in emerging economies tends to be rather volatile, we rely on a dynamic approach projecting key balance sheet items. The application of our proposed stress test framework to the Russian banking sector reveals high sensitivity of the capital adequacy ratio to the economic cycle. This shows up in both of the two-year macroeconomic scenarios considered: a baseline and an adverse one. Both scenarios indicate a need to increase the capital of the Russian banking sector. Furthermore, given that Russia's banking sector is small and fragmented by comparison with advanced economies, a loss of external financing could cause profound economic stress, especially for small and medium-sized enterprises. The Russian state has a low public debt-to-GDP ratio and plays a decisive role in the banking sector. These factors allow sufficient fiscal space for recapitalization of problematic banks under our proposed baseline and adverse scenarios.

\section{Introduction}

The recent global financial turmoil emphasized the importance of stress tests in evaluating the resilience of the financial sector to adverse macroeconomic shocks. ${ }^{1}$ Typically, financial sector supervisors and central banks have carried out macro stress tests in cooperation with key financial institutions. Unlike the stress tests financial firms perform for their own internal risk management purposes, however, the objective of macro stress testing is to identify potential sources of systemic risk and estimate the losses that key financial institutions in a given country might suffer under adverse macroeconomic developments or various shocks. The recent crisis also demonstrated that stress testing can serve as an important macroprudential tool for restoring confidence in financial systems, increasing transparency, and reducing market uncertainty. ${ }^{2}$

\footnotetext{
* Authors thank Thierry Bracke, Aaron Mehrotra, Iikka Korhonen, Laura Solanko and Laurent Weill for useful suggestions and comments. The views expressed in this paper are those of the authors and do not necessarily represent the views of any of the above-mentioned institutions. Financial support from the Grant Agency of the Czech Republic (GACR 403/10/1235) is gratefully acknowledged.

${ }^{1}$ Well before the current crisis, Borio, Furne, and Lowe (2001) pointed out the importance of stress tests in understanding risk and how risk relates to the economic cycle.
} 
Even though the adverse macroeconomic shocks of the recent global economic recession were largely generated in advanced economies, they impacted strongly on emerging markets. The decaying macroeconomic environment was felt strongest in the banking sectors of emerging economies with strong linkages to the international financial system. The fact that emerging markets can be highly vulnerable to this kind of adverse macroeconomic development stems from much higher volatility of credit growth than in advanced economies. Thus, to properly assess potential banking sector vulnerabilities, stress tests should reflect the actual conditions of emerging markets if they are to serve as an effective information device. Moreover, the adverse scenario needs to be sufficiently severe to expose systemic fragility, yet remain plausible. The formulation of an appropriate scenario for stress testing is discussed in Berkowitz (2000), who argues for a probabilistic scenario structure and backtesting.

Stress testing has been employed widely by regulators and private financial institutions, yet no clear consensus on the applied methodology has arisen. Most of the currently applied techniques are either based on academic research (Blaschke et al., 2001; Jones et al., 2004) or developed from practice-based guides published by central banks and international organizations (IMF and World Bank, 2005; Čihák, 2007).

Here, we employ a top-down approach to assess the resilience of the Russian banking sector to negative macroeconomic shocks. Our baseline and adverse macroeconomic scenarios are projected on individual bank balance sheets via simple econometric models that link non-performing loans and credit growth with selected macroeconomic indicators. We calculate credit, interest, and contagion risks for both the baseline and adverse scenarios. Using this information, we calculate the impact on bank capital for each bank, the sector as a whole, and groupings of banks broken down in terms of their size and ownership.

Our study contributes to the current literature in two ways. First, we use a unique data sample based on the balance sheets of banks that hold a total of about $94 \%$ of banking sector assets. This is important because the stability of Russia's bank-based financial system remains highly dependent on bank health and the Russian economy is so big that its stability might affect financial stability in other countries. Second, our methodology reflects the recent trend towards dynamic approaches. We employ a two-year time horizon to capture the deleveraging/releveraging process driven by swings in lending (Jakubík and Schmieder, 2008; Schmieder, Puhr, and Hasan, 2011). The impact of the deleveraging/releveraging process on the capital adequacy ratios of banks, although commonly omitted in the literature, is crucial in assessing Russia, as credit growth tends to be more volatile in emerging markets than in advanced economies. This is also reflected in higher volatility of capital needs due to higher volatility of credit exposures. Admittedly, this emerging economy phenomenon to some extent reflects lower levels of financial intermediation and catching-up needs, but it may also stem from the aggravated boom/bust cycles typical of these economies.

Our paper is structured as follows. Section 2 describes the main features of the Russian banking sector. Section 3 provides a description of our data sources and

\footnotetext{
${ }^{2}$ See, e.g., Bank of England (2008), Board of Governors of the Federal Reserve System (2009a, 2009b), Committee of European Banking Supervisors (2010), and European Banking Authority (2011).
} 
Table 1 Development of the Main Banking Sector Indicators (annual growth rates, \%)

\begin{tabular}{lrllllrr}
\hline & $\mathbf{2 0 0 4}$ & $\mathbf{2 0 0 5}$ & $\mathbf{2 0 0 6}$ & $\mathbf{2 0 0 7}$ & $\mathbf{2 0 0 8}$ & $\mathbf{2 0 0 9}$ & $\mathbf{2 0 1 0}$ \\
\hline Total assets & 27.3 & 36.6 & 44.0 & 44.1 & 39.2 & 5.0 & 14.9 \\
Capital (own funds) & 16.2 & 31.2 & 36.3 & 57.8 & 42.7 & 21.2 & 2.4 \\
Corporate loans & 38.0 & 31.3 & 39.8 & 51.5 & 34.3 & 0.3 & 12.1 \\
Household loans & 116.4 & 96.2 & 78.3 & 57.8 & 35.2 & -11.0 & 14.3 \\
Individual deposits & 30.4 & 39.4 & 38.0 & 35.4 & 14.5 & 26.7 & 31.2 \\
Corporate deposits & 36.9 & 43.7 & 52.6 & 47.2 & 24.4 & 8.9 & 16.4 \\
\hline
\end{tabular}

Source: Central Bank of Russia

stress test methodology. Section 4 presents and discusses our results. Conclusions are provided in Section 5.

\section{Main Features of the Russian Banking Sector}

Despite the large number of banks operating in Russia (955 at the end of 2010) and significant growth during the past decade (see Table 1), Russia's banking sector remains small and underdeveloped compared to economies of similar size. Indeed, banking sector assets only correspond to about $75 \%$ of GDP and only $40 \%$ of Russians have a bank account. Moreover, banking sector assets are concentrated in the major banks; the five largest banks hold almost half of the sector's total assets, and the 200 largest banks some 94\%. Other banks are typically quite small, even if they might have regional significance. Growth in credit to companies and households contributed to increasing financial intermediation by banks in Russia during the past decade, but the ratio of domestic credit to GDP in Russia is still below 50\% (as compared to over $100 \%$ in the Eurozone and China).

Unlike most countries in Central and Eastern Europe, no major bank privatization has occurred in Russia. Its banking sector remains predominantly statecontrolled to this day. Sberbank and VTB, Russia's two largest banks, held IPOs in 2007 that lifted the private shareholdings in these banks to $40 \%$ and $23 \%$, respectively. In October 2010, the Russian government approved a program to sell shares in numerous large state enterprises, including banks, over the next five years. In February 2011, VTB conducted a second public offering that resulting in the sale of a further $10 \%$ stake. Even so, the Russian state still owns about $75 \%$ of VTB. Similarly, the Central Bank of Russia (CBR), which currently holds a 57.6\% stake in Sberbank, plans to retain a 50\%-plus-one-share majority in the giant bank even after selling $7.6 \%$ of its shares in the near future. Although this is referred to as a "privatization program", the state will retain controlling voting shares in major banks and other "strategic" enterprises.

Like in other economies, Russia saw state control increase during the recent financial crisis. However, at the start of the crisis, state-controlled banks already accounted for over half of the Russian banking sector, and all of the country's five largest banks were state-controlled. These big banks acquired other banks during the crisis, further strengthening their market positions. Foreign participation in the Russian banking sector remains low, but has been increasing over the years. The number of banks with foreign ownership rose from 174 in 2000 to 220 at the end of 2010. About half of these banks are majority foreign-owned. Three of Russia's “Top 10" banks are foreign-owned (see Table 2). 
Table 2 "Top 10" Banks Based on Total Assets and Their Market Share (end of August 2011)

\begin{tabular}{lcc}
\cline { 2 - 3 } Bank & $\begin{array}{c}\text { \% of total } \\
\text { banking sector } \\
\text { assets }\end{array}$ & Ownership \\
\hline Sberbank & $27.0 \%$ & State (CBR) \\
Bank VTB & $9.7 \%$ & State \\
Gazprombank & $5.4 \%$ & State (Gazprom) \\
Rosselhozbank & $3.7 \%$ & State \\
VTB-24 & $3.0 \%$ & State \\
Alfa-bank & $2.5 \%$ & Domestic Private \\
Bank of Moscow & $2.3 \%$ & State* \\
UniCredit Bank & $2.3 \%$ & Foreign \\
Rosbank & $1.7 \%$ & Foreign \\
Raiffeisenbank & $1.6 \%$ & Foreign \\
\cline { 2 - 3 } & & \\
Sote: * through VTB & &
\end{tabular}

Russia's banking sector succumbed to the financial crisis in the second half of 2008. While banks were not directly exposed to the financial instruments that triggered the crisis, they and the rest of the Russian economy were hit with the double whammy of reduced access to foreign financing and a severe drop in oil prices.

The Russian government and the CBR swiftly responded by implementing measures aimed at maintaining the stability of the financial system. The emphasis was put on liquidity support for banks and maintaining the stability of the ruble. The implemented measures included a temporary decrease in bank reserve requirements, CBR guarantees for interbank lending to eligible banks, non-collateralized central bank loans, a wider range of acceptable collateral for Lombard and repurchase operations, as well as auctions allocating free budgetary funds to banks.

The deposit insurance framework was enhanced by increasing the deposit insurance limit, and Russia's deposit insurance agency assumed responsibility for restructuring individual troubled banks. Recapitalization of banks was accomplished directly by the government in the form of capital support for state-controlled banks, and indirectly in the form of unsecured subordinated loans from the CBR and development bank Vneshekonombank (VEB). In theory, both state-controlled and private banks had access to these subordinated loans, but the level of reliance on these loans depended on bank ownership. Private banks were recapitalized largely from other sources, while most of the capital increase of state-controlled banks was supplied in the form of subordinated loans. VEB was also given resources to help refinance the foreign debt of Russian firms. These measures helped stabilize Russia's banking system and boosted the state's presence in the banking industry, as the government took over troubled banks via state-controlled firms or banks to preserve trust in the banking sector and avert bank runs.

\footnotetext{
${ }^{3}$ Several foreign banks have recently decided to abandon their retail operations in Russia (Barclays, Banco Santander, HSBC). Moreover, $\mathrm{KBC}$ is selling its stake in Absolut Bank and Rabobank plans to concentrate on other countries. Last year, Morgan Stanley sold its local mortgage unit and Swedbank decided to curtail its operations as well. On the other hand, China Construction Bank has decided to enter the Russian market.
} 


\section{Data and Methodology}

The state's extensive participation in the Russian banking sector has strong implications for risk assessment for the sector. As borne out by the recent financial crisis, the Russian state has the will and resources to bail out troubled banks. Russia's interbank market, on the other hand, remains underdeveloped and dominated by the biggest banks. Most banks were shut out of the interbank market during the crisis, highlighting the lack of mutual trust in the banking community. Moreover, as most transactions are overnight, liquidity risk can be quite significant in the Russian conditions, especially for smaller banks.

\subsection{Data}

To assess the risks in the Russian banking sector more rigorously, we conduct a top-down macro stress test analysis. Unlike the bottom-up approach, the same models and assumptions are applied to all banks in our estimations. ${ }^{4}$ The analysis is based on the balance sheet data of Russian banks as of end-2009. The 200 largest banks, which together hold about $94 \%$ of Russian banking sector assets, are included in the analysis to assess banking sector vulnerabilities over a two-year horizon, i.e., we provide projections for 2010 and 2011. Our data come from the financial information agency Interfax, which collects and organizes bank data from the CBR. Aggregate indicators covering the development of the Russian banking sector originate from the CBR and at the time of writing were available for 2010. Data describing the macroeconomic environment are taken from Rosstat.

\subsection{Methodology}

Our methodology links bank balance sheet data and the macroeconomic environment under different scenarios. Adverse macroeconomic shocks are translated into capital adequacy ratios to assess financial sector resilience. Risks on bank balance sheets (credit, market, contagion, and income risks) are consistently covered within a single framework. Drehmann, Sorensen, and Stringa (2008), who point out the importance of off-balance sheet items as a potential source of risk, saw their assertion recently confirmed by the global financial crisis. Since these items are insignificant in the case of Russian bank balance sheets, however, we do not include them in our analysis.

We conduct the investigation in a dynamic framework in line with recent literature (Schmieder, Puhr, and Hasan, 2011). For each item of assets, liabilities, income, and expenditure, there is an initial (i.e., the last actually known) stock, to which the impact of the shock in one year is added. This final stock is then used as the initial stock for the following year. The changes in flow and stock variables are modeled in a consistent manner. Thus, losses reflected in a fall of profit (a flow indicator) will also be reflected in the same amount in total assets (a stock indicator). The dynamic nature of the analysis provides more realistic insights into banking sector vulnerabilities than sensitivity analyses or the commonly used static stress tests (Cihak, 2007).

\footnotetext{
${ }^{4}$ Some central banks use a combined top-down/bottom-up approach, e.g., the Dutch central bank (see Van den End, Hoeberichts, and Tabbae, 2006).
} 
Our stress test analysis is performed in five steps:

(ii) forecasting of stress parameters by "satellite" models,

(iii) deduction of losses from bank capital,

(iv) iterative interbank contagion,

(v) computation of post-shock and post-contagion capital adequacy ratios.

In step one, we create two macroeconomic scenarios for 2010-11. These are generated on the basis of publicly available professional consensus forecasts (baseline scenario) and expert judgment (adverse scenario). The scenarios include real GDP, inflation, the exchange rate between the Russian ruble and the U.S. dollar, and short-term interest rates. ${ }^{5}$ These variables are then used to project housing prices and the development of key credit variables, including non-performing loans (NPLs) and total loans.

In the next step, econometric models for aggregate data linking NPL ratio growth, total banking loan growth and housing prices to past GDP growth and other lagged economic and financial variables are employed to forecast credit growth, nonperforming loan ratio growth, and the growth rate of housing prices for the baseline and the adverse scenario. These are estimated independently as follows:

$$
\begin{aligned}
& \text { gnpl }_{t_{c, h}}=\alpha+\beta_{1_{c, h}} \text { realGDP } P_{t-1}+\beta_{2_{c, h}} \text { realGDP } P_{t-2}+\ldots+\beta_{k_{c, h}} \text { realGDP } P_{t-k}+\lambda_{c, h} \mathbf{X}+\varepsilon_{1 t_{c, h}} \\
& \text { gLoans }_{c, h}=\theta+\gamma_{1_{c, h}} \text { realGDP } P_{t-1}+\gamma_{2_{c, h}} \text { realGDP } P_{t-2}+\ldots+\gamma_{k_{c, h}} \text { realGDP }_{t-k}+\chi_{c, h} \mathbf{Y}+\varepsilon_{2 t_{c, h}} \\
& \text { gHousep }_{t}=\mu+\delta_{1} \text { realGDP }_{t-1}+\delta_{2} \text { realGDP }_{t-2}+\ldots+\delta_{k} \text { realGDP }_{t-k}+\tau \mathbf{Z}+\varepsilon_{3 t}
\end{aligned}
$$

where the lag structure is determined by statistical significance and $\mathbf{X}, \mathbf{Y}$, and $\mathbf{Z}$ are vectors of other control variables, such as nominal GDP, the NPL ratio, housing prices, and household credit growth.

These "satellite" models help us project credit growth and the NPL ratios for both the household (index $h$ ) and corporate (index $c$ ) sector consistently with the macroeconomic scenarios considered. The same growth rates are applied to all banks in the analysis.

In the third step, we use our projected values and balance sheet data to calculate credit and market risks (including both foreign-exchange and interest-rate risks) for each bank over the two-year horizon. The value of the risks is then deducted from total bank capital.

Market risk is evaluated based on the changes in interest rates and exchange rates. With respect to interest-rate risk, we consider changes in the present value of investment securities available for sale (trading book), in particular corporate, foreign government, federal, and municipal bonds. Their present value is influenced by changes in short-term interest rates that originate from the macroeconomic scenario under consideration. Again, a parallel move in the yield curve is assumed. As data on duration are not available at the level of individual banks, we estimate the average duration for available securities on the Russian market. We split securities into corporate bonds, federal loans, municipal bonds, and foreign government bonds.

\footnotetext{
${ }^{5}$ A parallel shift of the yield curve is assumed for simplification in further calculations.
} 
Based on CBR (2010) data for the sector, the same durations are assumed for all banks (1.7 for corporate bonds, 4.3 for federal loans and municipal bonds, and 1 for foreign government bonds). Finally, the sum of the changes in value for all the mentioned segments based on standard Macaulay duration is calculated for the interest-rate risk of every bank. The exchange-rate risk for each bank is calculated as the product of the net open foreign exchange position and the change in the exchange rate resulting from the macroeconomic scenario under consideration. Hedging against foreign exchange risk is not taken into account (as this information is not available), so that foreign exchange risk might be overestimated in some cases. The same caveats also apply to the interest-rate risk calculation.

Credit risk is traditionally the key risk for banks. This is particularly true for the Russian banking sector, which is mainly involved in commercial banking. The Russian economy was strongly affected by the crisis and experienced a sharp fall in economic output in 2009. As a result, NPLs in the local banking sector rose considerably. This increase in credit risk took place against the backdrop of a pronounced local boom-bust cycle. Annual credit expansion rates exceeded $40 \%$ before the crisis, collapsed to $-2.5 \%$ during the crisis in 2009 , and then rebounded to over $12 \%$ growth in 2010 . The credit risk that built up during the boom period, when lending standards were lowered, materialized during the bust period, when credit growth collapsed, leading with some time lag to a sharp rise in non-performing loans. This is in line with the evidence from other countries. For example, Jiménez and Saurina (2006) look at the Spanish data and show that credit granted during "good times" has a greater likelihood of ending up in default than loans made during recessions.

Due to the crucial impact of credit risk on bank balance sheets, macroeconomic credit-risk modeling often links credit risk and the macroeconomic environment. Some researchers highlight the non-linear relationship between macroeconomic shocks and credit risk (e.g., Cihak, 2007; Jakubík, 2007). Moreover, the non-linear logistic function originally introduced in credit-risk modeling by Wilson (1997a, $1997 b$ ) is often employed in credit-risk modelling. ${ }^{6}$ If appropriate data is available, the probability of default can be modeled directly (Hamerle, Liebig, and Scheule, 2004). However, this information is rarely available, so NPL data are employed in credit-risk modeling. This is also the case here.

For the analysis, we calculate credit risk for each bank, distinguishing between corporate and household loan portfolios. Expected credit losses are calculated as the product of the average probability of default (PD) for the loan portfolio, the exposure at default (EAD), and the loss given default (LGD). Due to the lack of LGD data for individual banks, we use the sector averages for corporate, household, and other exposures (59\% for corporate exposures, 55\% for households, and 58\% for others) based on estimations performed by rating agencies as initial values for $2009 .^{7}$ The LGD projection uses a simple econometric model for housing prices. The exposure at default can be expressed as the difference between outstanding loans and NPLs. Projected NPLs depend on new NPLs (determined by PD estimates), outflows

${ }^{6}$ See Boss et al. (2006), Boss et al. (2009), Virolainen (2004), and Jokivuolle, Virolainen, and Vahamaa (2008), among others.

${ }^{7}$ Moody's Global Banking Report for Russia was used for the calibration—see Moody’s (2010). 
(as write-offs or selling-out of existing NPLs), and the current stock of NPLs. This is expressed formally as:

$$
N P L_{t+1}=N P L_{t}+P D_{t} \cdot\left(\text { Loans }_{t}-N P L_{t}\right)-r \cdot N P L_{t}
$$

where $r$ represents the average write-off (or sell-out) rate of existing NPLs. In practice, this parameter can be unstable over time. For instance, in times of crisis, banks may increase the pace of write-offs to clean up their portfolios. This parameter is hard to model, so we set a constant value based on common practices in the Russian banking sector and anecdotal evidence. We employ the value $10 \%$ for corporate and other exposures, and $20 \%$ for household exposures. ${ }^{8}$

The estimated regression models for growth in the NPL ratio $(g n p l)$ and credit growth (gLoans) are then used to indirectly derive the probability of default for loans to corporations and households separately. The growth of the NPL ratio can be expressed in terms of the growth rate of the NPL stock and credit growth, i.e.:

$$
\text { gnpl }_{t}=\frac{\text { SNPL }_{t}+1}{\text { gLoans }_{t}+1}-1 \approx g N P L_{t}-\text { gLoans }_{t}
$$

where

$$
g N P L_{t}=\frac{N P L_{t}-N P L_{t-1}}{N P L_{t-1}} \quad \text { gLoans }_{t}=\frac{\text { Loans }_{t}-\text { Loans }_{t-1}}{\text { Loans }_{t-1}}
$$

The expected probability of default $(P D)$ is derived from the NPL ratio and credit growth projections. The probability of default is calculated as:

$$
P D_{t}=\left(g N P L_{t+1}+r\right) n p l_{t}
$$

Equation (6) suggests that the portfolio-average $P D$ depends on the average write-off rate $(r)$, the initial level of the NPL ratio, and the growth rate of NPLs, calculated as:

$$
g N P L_{t}=\left(\text { gnpl }_{t}+1\right)\left(\text { gLoans }_{t}+1\right)-1
$$

To account for unexpected losses, we use the Basel II formula, as it considers changes in risk-weighted assets (RWA). This allows us to project RWA so that the deleveraging/releveraging effects that characterize the high volatility of Russian credit growth can be taken into account by satellite models for credit growth. ${ }^{9}$ A change in RWA also affects the bank risk profile.

For the calculation of credit risk, we assume all banks behave as if they were complying with the Basel II framework, even though it is not fully implemented in Russia. Hence, the loan portfolio is split into corporate loans, retail loans, and other loans. Credit risk is computed using separate formulas as indicated in the Basel II framework. For the capital requirement for corporate loans, we proceed as follows:

\footnotetext{
${ }^{8}$ These numbers imply that banks on average keep bad loans on their balance sheets for ten years in the case of corporate and other exposures, and five years in the case of household exposures, before they write them off or sell them.

${ }^{9}$ This approach is in line with Schmieder et al. (2011). It was previously also applied by Jakubík and Schmieder (2008).
} 
Correlation $(R)=0.12 \times(1-E X P(-0 \times P D)) /(1-E X P(-50))+$

$$
+0.24 \times[1-(1-\operatorname{EXP}(-50 \times P D)) /(1-E X P(-50))]
$$

Maturity adjustment $(b)=(0.11852-0.05478 \times \ln (P D))^{\wedge} 2$

Capital requirement $(K)=\left[L G D \times N\left[(1-R)^{\wedge}-0.5 \times G(P D)+\right.\right.$

$$
\begin{aligned}
& \left.\left.+(R /(1-R))^{\wedge} 0.5 \times G(0.999)\right]-P D \times L G D\right] \times \\
& \times(1-1.5 \times b)^{\wedge}(-1) \times(1+(M-2.5) \times b)
\end{aligned}
$$

In the case of the capital requirement for retail loans, we use the following:

$$
\begin{aligned}
\text { Correlation }(R)= & 0.03 \times(1-\operatorname{EXP}(-35 \times P D)) /(1-\operatorname{EXP}(-35))+0.16 \times \\
& \times[1-(1-\operatorname{EXP}(-35 \times P D)) /(1-\operatorname{EXP}(-35))]
\end{aligned}
$$

Capital requirement $(K)=L G D \times N\left[(1-R)^{\wedge}-0.5 \times G(P D)+(R /(1-R))^{\wedge} 0.5 \times\right.$

$$
\times G(0.999)]-P D \times L G D
$$

where $N$ denotes normal distribution function and $G$ inverse normal distribution function. For "other loans", the same formula as for corporate loans is applied. The capital requirements for market and operational risk are assumed to grow at the same rate as the capital requirement for credit risk.

Expected losses are calculated separately for credit and market risk, and then deducted from total capital. Unexpected losses are covered by the Basel II formula so as to take into account the change in risk-weighted assets:

Expected losses $(E L)=E A D \times P D \times L G D$

Risk-weighted assets $(R W A)=K \times(1 / M C A R) \times E A D$

where $E A D$ denotes exposure at default and $M C A R$ is the minimum capital adequacy ratio ( $10 \%$ for Russia).

The losses stemming from the described credit and market risk calculations can to some extent be covered by available net income. Therefore, bank income is taken into account as the first line of defense against the losses. In particular, it is assumed that banks will use all available income to sustain their capital adequacy ratio at the same level when hit by a financial shock. If income is insufficient to fully absorb the losses emerging in the macroeconomic scenario under consideration, the losses are deducted from bank capital. Net income is computed as the sum of net interest income and non-interest income. The change in the interest rate based on the considered scenario and the average net interest income over the last three years is considered in order to project the total net interest income. Non-interest income is projected as the average over the last three years.

In the fourth step of our analysis, we take into account possible interbank contagion. After losses are deducted from bank capital, mapping of capital ratios into the probability of default of the respective bank (bank-specific $P D$ ) is used to determine the likelihood of the bank under consideration defaulting on its interbank liabilities to other banks. To consider interactive rounds of interbank contagion, we 
Table 3 Mapping of Bank CAR into PD (in \%

\begin{tabular}{rr}
\hline CAR $>=$ & PD \\
\hline 14.0 & 0.00 \\
12.0 & 0.01 \\
10.0 & 0.05 \\
8.0 & 5.00 \\
7.0 & 15.00 \\
5.0 & 50.00 \\
3.0 & 80.00 \\
$<3.0$ & 100.00 \\
\hline
\end{tabular}

approximate bilateral interbank exposures, which are unavailable, using the maximum entropy principle proposed by Upper and Worms (2002). Losses are computed using the default on interbank liabilities. The approximated bilateral interbank exposures are then multiplied by a bank-specific PD derived from expert-based mapping (see Table 3) of post-shock capital adequacy ratios into PDs. The LGD on a bank default is assumed to be $10 \%$.

The resulting losses are deducted from the capital of the affected banks. Ten iterations of such interbank contagion rounds are taken into account.

In the last step of our analysis, post-shock and post-contagion CARs that take into account the shock and interbank contagion are computed as the average of the banking sector and bank-by-bank capital adequacy ratios. Possible recapitalization costs that would arise if the capital adequacy ratio of a bank fell below the minimum regulatory requirement $(10 \%)$ are computed as a proportion of GDP. The recapitalization for the top 200 banks is scaled up to reflect their share of total banking sector assets.

\section{Empirical Analyses}

In this section, we present the results for the banking sector as a whole and the results for banks categorized on the basis of ownership and size.

\subsection{Results for the Banking Sector Overall}

The results of the stress test analysis suggest that the Russian banking sector is quite sensitive to changes in the macroeconomic environment. The high credit risk and cyclicality typical of emerging markets, combined with a low level of financial intermediation, appear to dampen economic development under our baseline scenario. While this probably reflects the low level of financial intermediation and catching-up needs of Russia, it also is an indication of aggravated boom/bust cycles. The CAR improvements in the Russian banking sector seen during 2009 and 2010 seem to be largely driven by deleveraging - see Figure 1 .

Banks on average appeared to be adequately capitalized at the end of 2010. The macroeconomic recovery that started in 2010 continues in 2011 under the baseline scenario. This is reflected in an acceleration of credit growth, which, after a decline during the crisis, turns positive in 2010. The rate of credit growth is predicted to more than double in 2011, which might constitute a threat for certain banks. Even if the NPL stock stabilizes, certain banks might not be able to bear 
Figure 1 Results of the Macro Stress Test

\section{Macroeconomic scenarios (\%)}

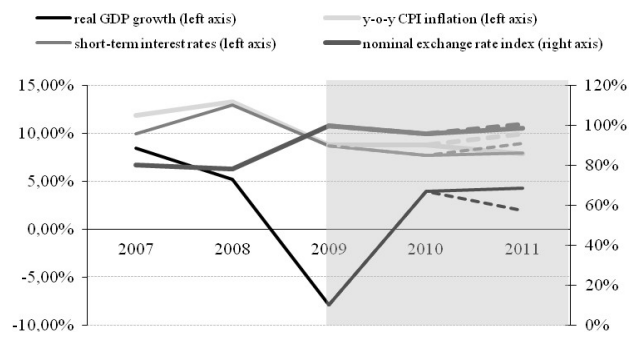

Notes: An increase in the nominal exchange rate index means depreciation. Solid line referes to "Baseline", dashed line to "Adverse" scenario.

Credit growth for both scenarios (\%, year-on-year)

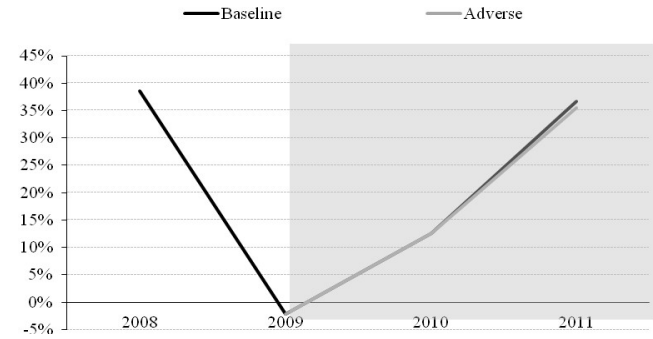

NPL ratios for the scenarios (\% of total loans)

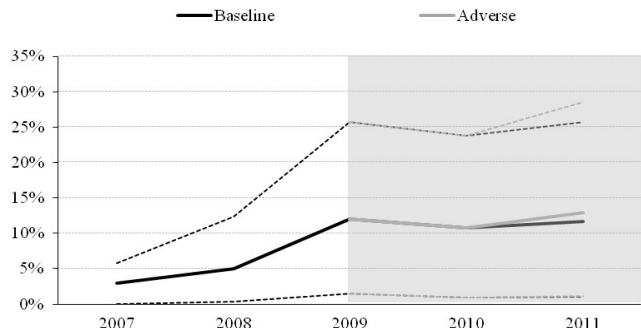

\section{Capital adequacy ratios after interbank contagion (\%)}

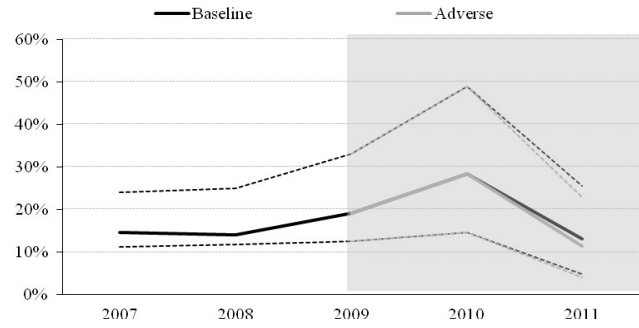

Notes: Capital a dequacy and non-performing loan ratios refer to the average (solid lines) and the $10^{\text {th }}$ and $90^{\text {th }}$ quantiles (dashed lines) for the 200 largest banks by total assets.

Sources: Bank of Finland Institute for Economies in Transition and ECB calculations. 
an acceleration in credit growth that puts downward pressure on their capital adequacy ratios. Based on our calculations, and provided that banks are unable to raise additional capital from other sources, the CAR for 67 banks out of the 200 included in our sample would fall below the regulatory minimum of $10 \%$ in 2011 and the total recapitalization costs would reach $0.6 \%$ GDP in 2011. On the other hand, the profitability of the banking sector in 2010 outpaced even the pre-crisis levels, which would help improve the situation of some banks in 2011. Moreover, statecontrolled banks could be recapitalized easily by the government and state support for domestic private banks could also be provided via state-controlled companies as in 2008 and 2009. In addition, some banks will have to increase their registered capital anyway when new minimum capital requirements of RUB 180 million (about $€ 4.6$ million) enter into force at the beginning of $2012 .^{10}$

Under our adverse scenario, which assumes only sluggish growth in 2011, the situation deteriorates further. As the macro data for 2010 and much of 2011 are already known, it is clear that this scenario is only hypothetical. The NPL ratio increases under the scenario to about $13 \%$, while the average CAR for all the banks included in our analysis remains above the regulatory minimum. ${ }^{11}$ Some 80 banks out of the 200 in our sample would need recapitalization in $2011 .^{12}$ The total recapitalization costs during 2011 would reach as high as $0.8 \%$ of GDP.

Taking into consideration Russia's low public debt-to-GDP ratio (just below $10 \%$ at the end of 2010), the government is fully able to recapitalize banks under each scenario without facing significant fiscal strains. Despite this, our analysis highlights some weaknesses in the Russian banking sector. The currently large average capital buffer $(18.1 \%$ at the end of 2010$)$ was partly the result of a substantial slowdown in credit growth (from over $40 \%$ annual nominal credit growth in the precrisis period to a decrease of about $2.5 \%$ in 2009). As the economy recovers, high credit growth could put downward pressure on the CAR from an increase in riskweighted assets and banks tightening credit conditions. Thus, the economic recovery could be dampened as access to external financing worsens, especially for small and medium-sized firms. Here, the capacity of the Russian banking sector to maintain the pre-crisis credit growth without generating additional risk would be limited. This reinforces the views that Russia's banking sector is under-sized for the size of the economy and that private sector actors still face serious constraints in access to bank financing. Even today, Russian corporations tend to rely on financing obtained from global markets if they can get it. (Figure 2)

\subsection{Results by Ownership}

One of the distinctive features of the Russian banking sector is the substantial role played by the state. While state-controlled banks are tacitly assured of being

\footnotetext{
${ }^{10}$ The minimum capital requirements at the time of writing were RUB 90 million. In December 2011, however, the president signed a new law that incrementally raises the minimum capital requirements for existing banks to RUB 300 million (about $€ 7.4$ million) by 2015 .

${ }^{11}$ This number has been adjusted to obtain a value comparable with the commonly used practices and does not correspond to the officially reported numbers provided in section 2 .

12 These results are in line with the stress test results conducted by the Central Bank of Russia (CBR, 2011), whereby about a third of all Russian banks would need to be recapitalized under our adverse scenario. The CBR results are based on bank-level data as of end-2010.
} 
Figure 2 Individual Results of Macro Stress Tests

CAR, baseline and adverse scenario in $2011(\%)$

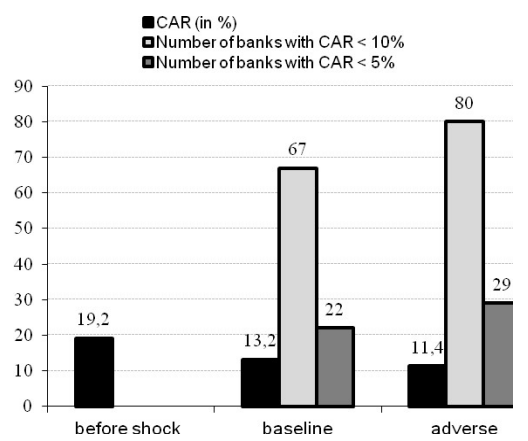

CAR and NPL ratios for baseline scenario in 2011

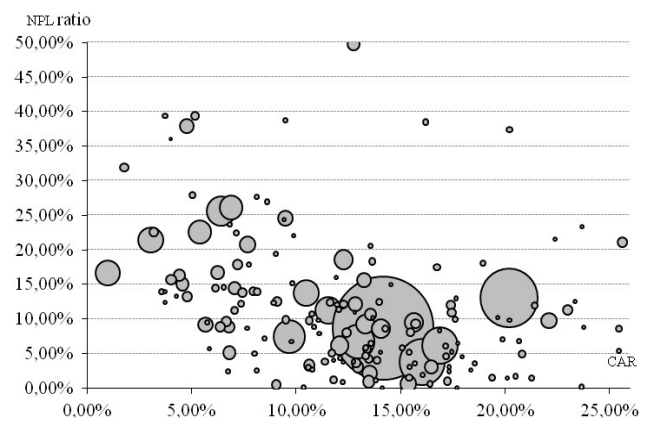

Notes: CAR (\%) is on the horizontal axis and NPLs (\% of total loans) are on the vertical axis. Bubble size corresponds to the bank's size in terms of assets.

\section{CAR and NPL ratios for adverse scenario in 2011}

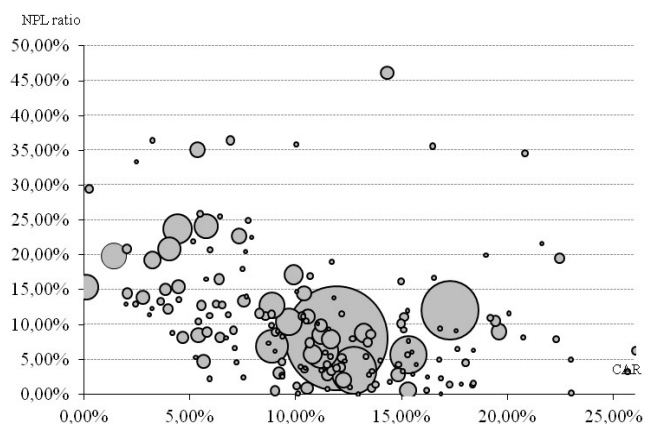

Notes: CAR (\%) is on the horizontal axis and NPLs (\% of total loans) are on the vertical axis. Bubble size corresponds to the bank's size in terms of assets.

Sources: Bank of Finland Institute for Economies in Transition and ECB calculations.Sources: Bank of Finland Institute for Economies in Transition and ECB calculations. 
bailed out in the event of financial distress, this tells us nothing about how vulnerable these banks actually are to macroeconomic downturns. To investigate this question, we divide the banks in our sample into three categories according to ownership. Foreign-owned banks are those where the foreign ownership share exceeds $50 \%$. State-controlled banks are identified based on the data from Vernikov (2009) updated at BOFIT. The last group consists of private domestic banks.

Our analysis reveals that all types of banks are highly sensitive to macroeconomic developments in the country. In line with the above-described results for the entire banking sector, the CAR of banks in all subgroups drops significantly in 2011 (even under the baseline scenario). The average CARs of foreign-owned and domestic private banks drop to near the regulatory minimum. The situation of statecontrolled banks seems a bit better, as the starting CAR level was higher for these banks; their average CAR does not fall below $15 \%$ under the baseline scenario in 2011. Moreover, state-controlled banks can rely on relatively stable household deposits and access to CBR financing as necessary.

Foreign-owned banks seem the most vulnerable. Almost half of foreign-owned banks under the baseline scenario and over half under the adverse scenario see their CARs fall below the regulatory minimum without infusions of fresh capital. The recapitalization costs here amount to almost $0.3 \%$ of GDP under the baseline scenario, and are even higher under the adverse scenario for 2011. Prior to the European debt crisis, at least, the working assumption was that these banks have strong parent companies that would have little trouble providing additional capital infusions under normal circumstances.

Similar recapitalization costs as in the case of foreign-owned banks would be necessary for domestic private banks. Some $30 \%$ of these banks under the baseline scenario and $40 \%$ in the adverse scenario would have CARs lower than the regulatory minimum required by the Russian regulator (10\%). For some of these banks, it could be challenging to increase their capital. Nevertheless, they could become interesting targets for acquisition by other banks. Russia's state-controlled banks have grown recently by acquiring other banks, a trend that is undoubtedly strengthening the role of state-controlled banks in all segments of the market.

Under our adverse scenario, the situation worsens for foreign-owned and domestic private banks. The average CAR falls below the regulatory minimum for these subgroups of banks in 2011.(Figure 3)

\subsection{Results by Size}

The fact that the Russian banking sector is so concentrated increases the relative importance of its largest banks. It is therefore prudent to analyze the results of our stress tests for different sized banks. We divide the banks in our sample into three categories (large, medium, and small) based on total assets. We apply two different sets of criteria to divide the banks into these subgroups, ${ }^{13}$ but both produce the results we now describe.

\footnotetext{
13 The large banks are Russia's ten largest banks by assets. Medium-sized banks are defined as either the eleventh to thirtieth largest banks, or alternatively, as the eleventh to fiftieth largest banks. The remaining banks in the Top 200 are considered to be small banks.
} 
Figure 3 Results of Macro Stress Test for Ownership Subgroups

\section{STATE-CONTROLLED BANKS}

CAR after interbank contagion (\%)

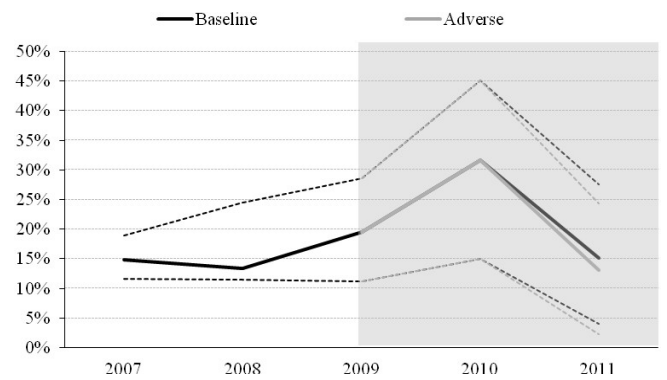

FOREIGN-OWNED BANKS

CAR after interbank contagion (\%)

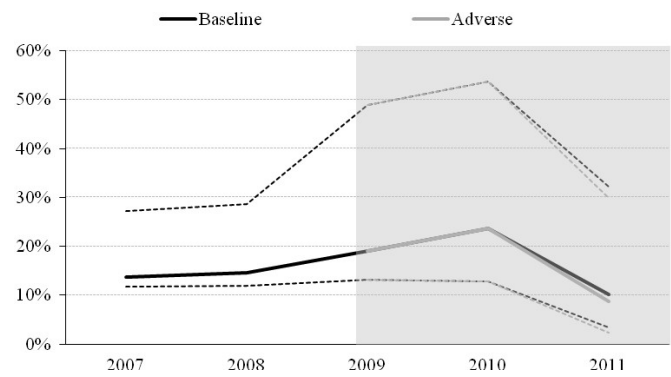

DOMESTIC-PRIVATE BANKS

CAR after interbank contagion (\%)

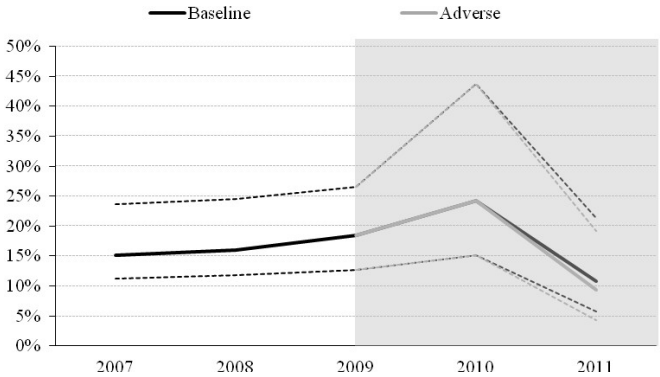

Notes: Capital adequacy and non-performing loan ratios refer to the average (solid lines) and the $10^{\text {th }}$ and $90^{\text {th }}$ quantiles (dashed lines) for the 200 largest banks by total assets.

Sources: Bank of Finland Institute for Economies in Transition and ECB calculations.

Our analysis suggests medium-sized banks are the most vulnerable. Even under the baseline scenario, about half of medium-sized banks end up with CARs lower than the regulatory minimum and the average CAR for all medium-sized banks drops below the minimum level. On the other hand, the average CAR of both large 
Figure 4 Results of Macro Stress Test for Size Subgroups

LARGE BANKS

CAR after interbank contagion (\%)

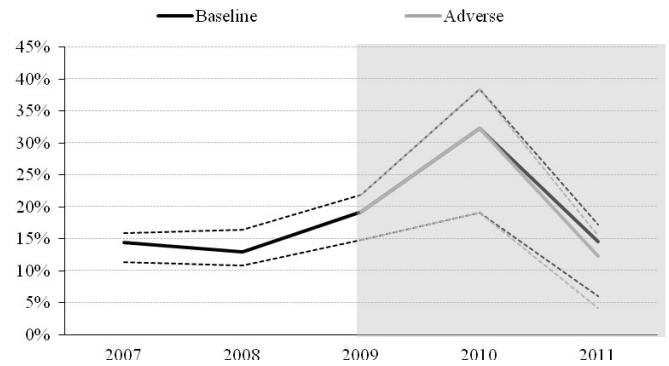

MEDIUM-SIZED BANKS

CAR after interbank contagion (\%)

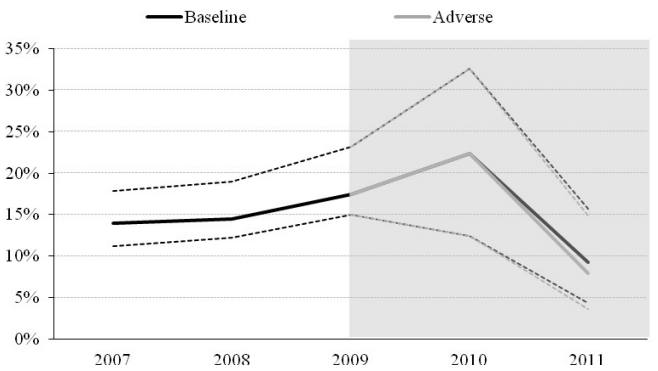

SMALL BANKS

CAR after interbank contagion (\%)

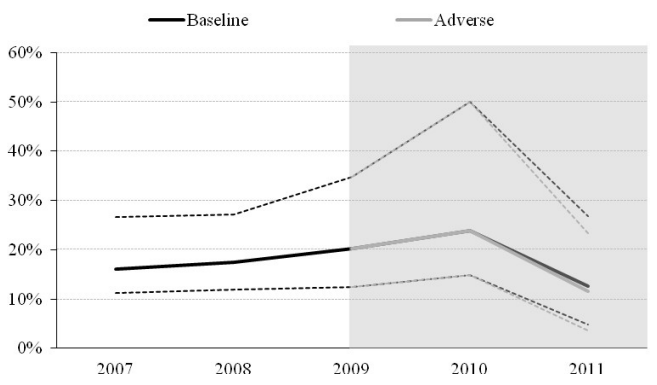

Notes: Large banks are defined as the ten largest banks by assets, medium-sized as the eleventh to thirtieth largest banks and the rest are considered to be small. Capital adequacy and non-performing loan ratios refer to the average (solid lines) and the 10th and 90th quantile (dashed lines) for the 200 largest banks by total assets.

Sources: Bank of Finland Institute for Economies in Transition and ECB calculations.

and small banks does not fall below the $10 \%$ minimum even under the adverse scenario. Large and small banks tend to be a bit better capitalized than medium-sized banks, but their CAR declines are also not as sharp. Medium-sized banks are 
systemically important, since they are large enough to precipitate major bank runs. The recapitalization costs that would be necessary for medium-sized banks under the adverse scenario if they were not able to raise new capital in any other way would reach approximately $0.3 \%$ of GDP.

Unlike medium-sized banks, small banks seem largely resilient to deterioration in the macroeconomic environment. A possible explanation for this phenomenon is that they typically operate within a small region and focus on some specific businesses they know well. Such a strategy probably makes it easier to manage risk. Moreover, small banks on average hold substantial capital buffers. On the other hand, in comparison to large banks it is more difficult and more costly for medium-sized banks to acquire capital, which makes them more vulnerable than large banks. (Figure 4)

\section{Conclusions}

A healthy financial sector is necessary for sustainable economic growth. Hence, it is crucial to assess the risks and potential vulnerabilities of the banking sector. Our paper proposes a top-down stress test methodology that employs relatively limited information. This is especially important in emerging markets, where short time series, structural breaks, and limited data availability with an absence of reliable market data can make banking sector analyses quite challenging. Moreover, credit growth in emerging economies tends to be rather volatile, especially when compared to advanced economies. This aspect of emerging economies has an important implication for the choice of stress-testing methodology, as such volatility influences the risk-weighted assets in bank portfolios. While a commonly used static framework assuming constant balance sheet items over the projected horizon can be sufficient for an advanced economy, it can substantially bias the results for emerging economies, where the amount of total loans can as much as double over a short period of time. Thus, a dynamic approach projecting key balance sheet items may better capture the high volatility of credit growth typical of emerging economies.

Moreover, proper analysis of banking sector vulnerabilities is essential to address potential financial instability in an adequate and timely manner. Stress tests constitute an important part of financial stability assessment, helping regulators and policymakers respond appropriately to changing macroeconomic conditions.

Russia's financial system is bank-based. Important sources of risk in the sector can easily be overlooked in aggregate banking sector numbers. Hence, we employ individual bank-level data to detect possible banking sector vulnerabilities. A topdown macro stress test approach is applied here to assess the stability of the Russian banking sector. We consider the 200 largest banks, which account for $94 \%$ of the banking sector's assets. Using the stress test framework we consistently evaluate the risks on bank balance sheets (credit, market, contagion, and income risks). Moreover, the dynamic approach employed allows us to capture the impact of the re/de-leveraging effect on banks' balance sheets, which is especially important for emerging markets like Russia. We analyze the banking sector as a whole, as well as the resilience of subgroups based on bank size and ownership. The two-year horizon applied is shown to better explain the long-term nature of credit risk than the commonly used one-year horizon. 
Our analysis backs up the view that the Russian banking sector is under-sized for the size of the economy and that the private sector is likely to face difficulties in obtaining external financing when macroeconomic conditions deteriorate. The Russian banking sector remains dominated by state-controlled banks, which are less vulnerable to global financial problems than foreign-owned banks. In any case, the government still has sufficient fiscal space to recapitalize the banks in a downturn. This was illustrated in summer 2011 with the massive public rescue of Bank of Moscow with a $\$ 14$ billion bailout package. Our analysis further shows that medium-sized banks are on average more vulnerable than large and small banks.

As a policy note, Russian banks in general should be expected to bolster their capital as economic growth recovers. Here, it is important to keep in mind that we assume no increase in bank capital in our calculations. In general, bank capital was growing at about 38\% on average in the pre-crisis period of 2001-2007. If the banking sector returns to growth, only some banks for which we have identified CARs below the minimum requirement would actually face shortage of capital. Nevertheless, the limited ability of the banking sector to finance the real sector could curtail Russian economic growth over the medium and long term.

\section{REFERENCES}

Bank of England (2008): Financial Stability Report. October.

Berkowitz J (2000): A Coherent Framework for Stress Testing. Journal of Risk, 2(2):1-11.

Blaschke W, Jones M, Majnoni G, Peria M (2001): Stress Testing of Financial Systems: An Overview of Issues, Methodologies, and FSAP Experiences. IMF Working Paper, no. 01/88.

Board of Governors of the Federal Reserve System (2009a): The Supervisory Capital Assessment Program: Design and Implementation.

http://www.federalreserve.gov/bankinforeg/bcreg20090424a1.pdf.

Board of Governors of the Federal Reserve System (2009b): The Supervisory Capital Assessment Program: Overview of Results.

http://www.federalreserve.gov/newsevents/press/bcreg/bcreg20090507a1.pdf.

Borio C, Furfine C, Lowe P (2001): Procyclicality of the Financial System and Financial Stability Issues and Policy Options. BIS Papers, no. 1.

Boss M, Fenz G, Pann J, Puhr C, Schneider M, Ubl E (2009): Modeling Credit Risk through the Austrian Business Cycle: An Update of the OeNB Model. Oesterreichische Nationalbank, Financial Stability Report, no. 17:85-101.

Boss M, Krenn G, Pann J, Puhr C, Summer M (2006): Systemic Risk Monitor: A Model for Systemic Risk Analysis and Stress Testing of Banking Systems. Oesterreichische Nationalbank, Financial Stability Report, no. 11:83-95.

Central Bank of the Russian Federation (2010): Obzor finansovogo rynka (Financial Market Review), 69(2).

Central Bank of the Russian Federation (2011): Banking Supervision Report 2010.

Čihák M (2007): Introduction to Applied Stress Testing. IMF Working Paper, no. 07/59.

Committee of European Banking Supervisors (2010): Aggregate outcome of the 2010 EU wide stress testing exercise coordinated by CEBS in cooperation with the ECB.

Drehmann M, Sorensen S, Stringa M (2008): The Integrated Impact of Credit and Interest Rate Risk on Banks: An Economic Value and Capital Adequacy Perspective. Bank of England, Working Paper, no. 339. 
End JW van den, M. Hoeberichts M, Tabbae M (2006): Modelling Scenario Analysis and Macro Stress-testing. De Nederlandsche Bank Working Paper, no. 119.

European Banking Authority (2011): 2011 EU-Wide Stress Test Aggregate Report. July.

Hamerle A, Liebig T, Scheule H (2004): Forecasting Credit Portfolio Risk. Deutsche Bundesbank, Discussion Paper, Series 2: Banking and Financial Supervision, no.01/2004.

IMF and World Bank (2005): Financial Sector Assessment: A Handbook.

Jakubík P (2007): Macroeconomic Environment and Credit Risk. Finance a úvěr-Czech Journal of Economics and Finance, 57(1-2):41-59.

Jakubík P, Schmieder Ch (2008): Stress Testing Credit Risk: Is the Czech Republic Different from Germany? Czech National Bank, Working Papers, no. 9.

Jiménez G, Saurina J (2006): Credit Cycles, Credit Risk, and Prudential Regulation. International Journal of Central Banking, June:65-98.

Jokivuolle E, Virolainen K, Vahamaa O (2008): Macro-Model-Based Stress Testing of Basel II Capital Requirements. Bank of Finland Research Discussion Paper, no. 17.

Jones M, Hilbers P, Slack G (2004): Stress Testing Financial Systems: What to Do When the Governor Calls. IMF Working Paper, no. 04/127.

Moody's (2010): Moody's Global Banking—Russia. Banking System Outlook.

Schmieder Ch, Puhr C, Hasan M (2011): Next Generation Balance Sheet Stress Testing. IMF Working Paper, no. 11/83.

Upper C, Worms A (2002): Estimating Bilateral Exposures in the German Interbank Market: Is there a Danger of Contagion? Bundesbank Discussion Paper, no. 09/02.

Vernikov A (2009): Russian Banking: The State Makes a Comeback. BOFIT Discussion Paper, no. 24.

Virolainen K (2004): Macro Stress Testing with a Macroeconomic Credit Risk Model for Finland. BOFIT Discussion Paper, no. 12.

Wilson TC (1997a): Portfolio Credit Risk I. Risk Magazine, 10(9):111-117.

Wilson TC (1997b): Portfolio Credit Risk II. Risk Magazine, 10(10):56-61. 